\title{
Wheeze in the absence of asthma at age 8-10 is not associated with atopy in Manitoba children
}

\author{
Mathieu F Cooney ${ }^{1 *}$, Jennifer LP Protudjer ${ }^{1,2}$, Anita L Kozyrskyj ${ }^{2,3}$, Allan B Becker ${ }^{1,3}$ \\ From AllerGen NCE Inc.'s Fifth Annual Research Conference: Innovation from Cell to Society \\ Québec City, QC, Canada. 7-9 February 2010
}

\begin{abstract}
Background
Atopy in children with recurrent wheeze is the best predictor for persistent asthma. A high prevalence of atopy was found in children with recurrent wheeze who were at high risk of developing persistent asthma based on the Asthma Predictive Index (API)[1]. A newly modified API now includes allergic sensitization to aeroallergens and to foods as criteria for the risk assessment of persistent asthma in children with recurrent wheeze. However, associations between wheeze and atopy in the absence of asthma have not been extensively examined. Since atopy is considered a risk marker for asthma in children with recurrent wheeze, we predicted that it would not be associated with wheeze when asthma was absent.
\end{abstract}

\section{Materials and methods}

Children in the 1995 Manitoba Birth Cohort (SAGE) nested case-control study were assessed at age 8-10 years by a pediatric allergist both clinically and by questionnaire. Skin-prick tests to common allergens were performed to determine the presence of atopy. Children underwent methacholine challenge for airway hyperresponsiveness. Parent-reported history of wheeze ever was ascertained using the question "Has your child ever had wheezing or whistling in the chest at any time in the past?" The association between atopy and recurrent wheeze was determined using the odds ratio (OR) and $95 \%$ confidence interval $(\mathrm{CI})$.

\section{Results}

723 (404 [55.9\%] boys) children were involved in this study (mean age $9.08 \pm 0.53) .246(34.1 \%$ [149 (36.9\%) boys]) had pediatric allergist-diagnosed asthma. 236/714

\footnotetext{
* Correspondence: mcooney@mich.ca

${ }^{1}$ Manitoba Institue of Child Health, Winnipeg, Manitoba, Canada, R3E 3P4

Full list of author information is available at the end of the article
}

(33.1\%) children assessed had current wheeze based on allergist notes and 420 (58.4\%) had parent-reported wheeze ever; these were not mutually exclusive. There was a significant association between atopy and parentreported wheeze ever (OR 2.16; 95\% CI 1.59-2.94), physician-noted wheeze with a cold (OR 2.23; 95\% CI 1.653.00) and without a cold (OR 1.82; 95\% CI 1.33-2.50). Physician-noted wheeze without a cold was more strongly associated with atopy in girls (OR 2.41; 95\% CI 1.48-3.93) compared to boys (OR 1.46; $95 \%$ CI 0.96 2.22). In the absence of asthma, the association between atopy and parent-reported wheeze ever, physician-noted wheeze with a cold and without a cold was lost. Further stratification by $\mathrm{PC}_{20}$ category did not yield significant associations.

\section{Conclusions}

Atopy is an important diagnostic marker in the pediatric clinical assessment of wheeze. As predicted, wheeze not used in the diagnosis of asthma was not associated with atopy. These results support the use of a modified API that includes allergic sensitization to aeroallergens and foods for its positive predictive value.

\section{Author details}

${ }^{1}$ Manitoba Institue of Child Health, Winnipeg, Manitoba, Canada, R3E 3P4. ${ }^{2}$ University of Manitoba, Winnipeg, Manitoba, Canada, R3E 3P4. ${ }^{3}$ University of Alberta, Edmonton, Alberta, Canada, R3E 3P4.

Published: 26 November 2010

\section{Reference}

1. Guilbert TW, Morgan WJ, Zeiger RS, Bacharier LB, Boehmer SJ, Krawiec M, et al: Atopic characteristics of children with recurrent wheezing at high risk for the development of childhood asthma. J Allergy Clin Immunol 2004, 114(6):1282-7.

doi:10.1186/1710-1492-6-S3-P30

Cite this article as: Cooney et al:: Wheeze in the absence of asthma at age $8-10$ is not associated with atopy in Manitoba children. Allergy, Asthma \& Clinical Immunology 2010 6(Suppl 3):P30. 